\title{
COMPARISON OF THE MECHANICAL RESPONSE OF POROUS Ti-6AI-4V ALLOYS PRODUCED BY DIFFERENT COMPACTION TECHNIQUES
}

\author{
E. Erkan AŞIK ${ }^{1}$, Fatma ŞEN ${ }^{2}$, Gizem YAYMACI ${ }^{2}$, G. İpek SELIMOĞLU ${ }^{2, ~ * ~}$ \\ ${ }^{1}$ Faculty of Engineering Technology, University of Twente, Enschede, 7500AE, Netherlands \\ ${ }^{2}$ Department of Materials Science and Engineering, Anadolu University, Eskişehir, 26470, Türkiye
}

\begin{abstract}
Porous Ti-6Al-4V alloys are attractive candidates as implant materials due to their good biocompatibility combined with the porous structure leading to increased osseointegration and decreased stiffness. Accordingly, different processing techniques were employed for the production of Ti-6Al-4V foams in the literature. Among these techniques, sintering with space holder is used to produce porous Ti-6Al-4V alloys in this study. Magnesium was employed as the space holder material because of its relatively low boiling point as well as high oxygen affinity. Two different compaction techniques, die compaction with hydraulic pressing and cold isostatic pressing (CIP), were employed for obtaining green compacts. Both spherical and nonspherical Ti-6Al-4V powders were used to investigate the effect of powder shape on compaction. Processed foams were characterized in terms of both microstructural and mechanical aspects in order to investigate the effect of pressing conditions in combination with powder characteristics. It was observed that NS-CIP foam, which was produced by compacting nonspherical powders by cold isostatic press, has the highest strength. However, the S-DP foam, which was produced by diepressing of spherical powders, has the highest toughness.
\end{abstract}

Keywords: Hydraulic pressing, Cold isostatic pressing; Space holder technique; Magnesium; Compression behavior

\section{INTRODUCTION}

Titanium and its alloys have versatile combination of properties such as low density, high specific strength, high corrosion resistance, good fatigue resistance and biocompatibility which makes them unique for automotive [1] and aerospace industries [2] and biomedical applications [3-5]. In the recent years, porous titanium and titanium alloys are used extensively as biomedical materials for dental implants, hip and knee joints [6-8]. By controlling porosity content, mechanical properties of porous materials can be adjusted. For biomedical applications, this gives the opportunity to reduce elastic modulus of the implant to the elastic modulus value of the bone (5-30 MPa) to prevent stress-shielding effect, which is the weakening of the bone due to presence of stiffer implant material [9-10]. Furthermore, porous structure increases osseointegration and bone ingrowth establishing better mechanical adhesion of the implant to the bone tissue [11-13].

Porous titanium and titanium alloys are produced by solid state processes due to their high melting point and strong reactivity [14]. Loose powder sintering [15], space holder method [16,17], sintering of hollow spheres [18], gas entrapment method [19], replication method [20] and electron beam/laser melting of powders [21-23] are common techniques in literature for production of porous titanium and its alloys. From these techniques, space holder method has advantages in accurately controlling the fraction, size and shape of pores. Magnesium [24], sodium chloride [25], carbamide [26], starch [27], titanium hydride [28] and ice [29] are some of the space holders that are used in the production of porous titanium alloy structures. Among the space holders, magnesium is tempting due to its dual function; lower boiling point and higher oxygen affinity. During heating to the sintering temperature, which is above the boiling point of $\mathrm{Mg}$, magnesium first melts and creates macropores and then it

*Corresponding Author: ginakas@anadolu.edu.tr 
evaporates. The Mg vapor present in the furnace creates a protective gas atmosphere and prevents oxidation of titanium since $\mathrm{Mg}$ has got higher oxygen affinity [30].

Apart from pore characteristics, mechanical properties of implants are also important. The foams should have low stiffness but enough strength and ductility. Strut characteristics are important for mechanical strength since they are the load carrying parts of the porous structures and are mostly effected from sintering conditions (temperature and time), compaction of the powders (pressure), powder size and shape (spherical or angular).

In the present study, Ti-6Al-4V foams were produced with the presence of $60 \mathrm{vol} \% \mathrm{Mg}$ space holder from two different powders (spherical and non-spherical) by employing two different compaction methods (die pressing and cold isostatic pressing) in order to investigate their influence on mechanical properties of the foams.

\section{MATERIALS AND METHODS}

In this study, spherical and nonspherical Ti-6Al-4V powders (ASTM F1580-01, Phelly Materials Inc., New Jersey, U.S.A) and magnesium (Mg) powder (99.82 \% purity, TangShanWeiHao Magnesium Powder Co. LTD., Tangshan, Hebei Province, China) were used for the production of porous Ti-6Al$4 \mathrm{~V}$ foams.

Magnesium was used as space holder due to its low evaporation temperature and higher oxygen affinity than Ti-6Al-4V. Spherical Mg powders were sieved to the range of 250-600 $\mu \mathrm{m}$ since the final size and shape of the macropores will be determined by $\mathrm{Mg}$ powder characteristics.

Particle size distribution analysis of the Ti-6Al-4V and $\mathrm{Mg}$ powders was done by Malvern Mastersizer 2000 Particle Size Distribution (PSD) Analyzer, which is capable of measuring particle sizes in the range of $0.02-2000 \mu \mathrm{m}$ with an accuracy of $1 \%$. Both spherical and nonspherical Ti-6Al-4V powders as well as $\mathrm{Mg}$ powder used in this study exhibited Gaussian distribution with average particle sizes of $\sim 55, \sim 42$ and $\sim 375 \mu \mathrm{m}$, respectively (Figure 1).

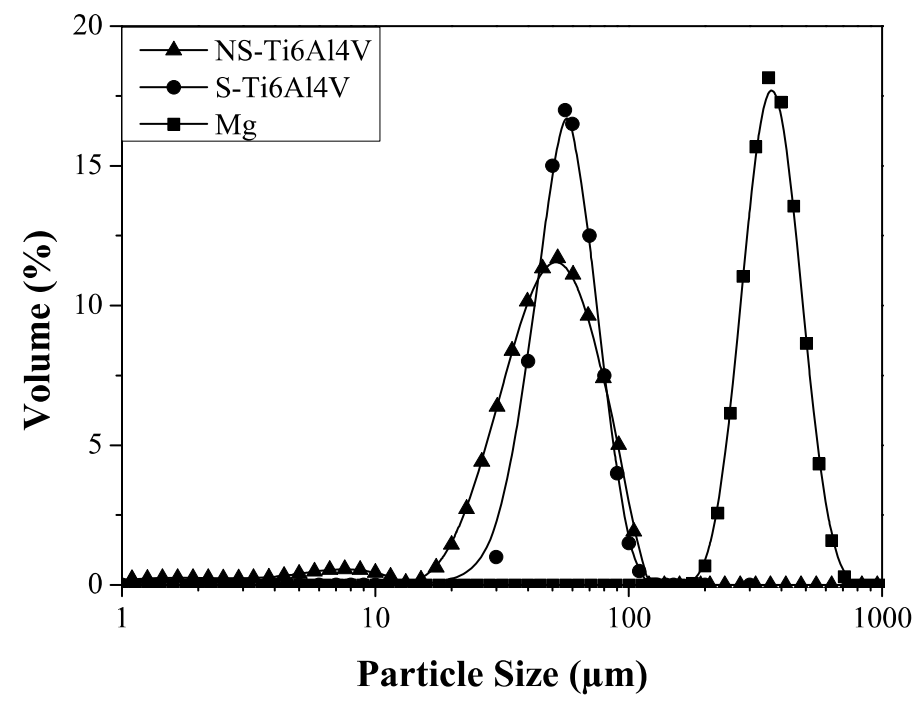

Figure 1. Particle size distribution of Ti-6Al-4V and Mg powders

The bimodal distribution of nonspherical Ti-6Al-4V powders was due to the plate-like shape of the powders (Figure 2a) giving rise to the difference in obtained result according to the side of the plate 
that the measurement taken. The spherical shape of Ti-6Al-4V (Figure 2b) powders was also revealed by SEM micrographs. The morphology of the powders, extent of sintering and pore structure of the produced Ti-6Al-4V foams were examined by scanning electron microscope (SEM) (Nova Nano SEM 430, FEI LTD, Oregon, USA).

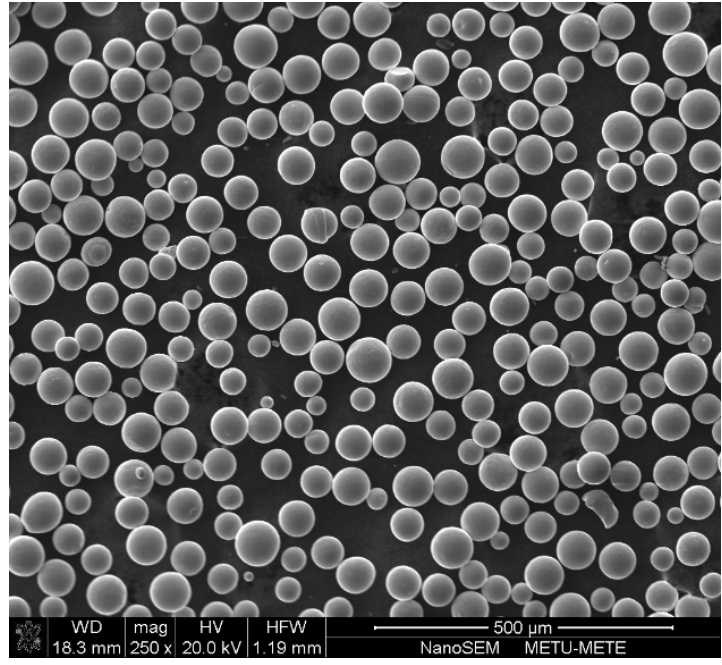

(a)

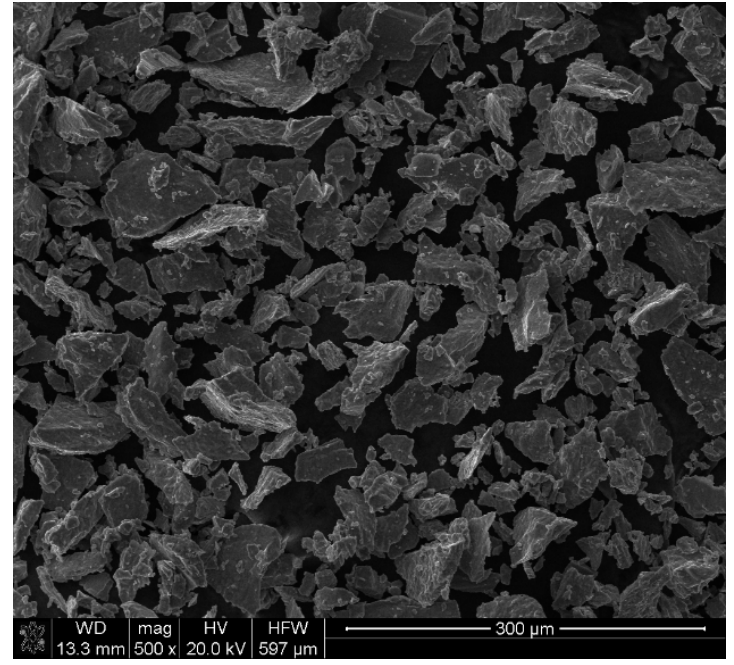

(b)

Figure 2. SEM micrographs of (a) spherical Ti-6Al-4V and (b) nonspherical Ti-6Al-4V

Ti-6Al-4V powders were mixed with $60 \mathrm{vol} \% \mathrm{Mg}$ powder and $5 \mathrm{wt} \%$ polyvinyl alcohol solution (2.5 $\mathrm{wt} \% \mathrm{PVA}+$ distilled water), which was used as binder. The mixture was blended homogenously until all $\mathrm{Mg}$ powders were covered with Ti-6Al-4V powders and the excess water in PVA solution got evaporated. Cylindrical compacts of spherical Ti-6Al-4V+Mg powder mixture were produced by both die and cold isostatic pressing. For die pressing, powder mixture was compacted in a double-ended steel die under $500 \mathrm{MPa}$ pressure by using hydraulic press (S-DP) while silicon molds were employed for cold isostatic pressing under $300 \mathrm{MPa}$ (S-CIP). Furthermore, cylindrical compacts of nonspherical Ti-6Al-4V+Mg powder mixture (NS-CIP) were obtained by employing CIP (Stansted Fluid Power Ltd., Harlow, United Kingdom) to investigate the effect of powder shape on mechanical response. All of the compacts obtained were $10 \mathrm{~mm}$ in radius with an aspect ratio of 1 .

All of the compacts were sintered in a vertical tube furnace under high purity argon $(99.999 \%$ purity, $\mathrm{N}_{2}: 6.2 \mathrm{vpm}, \mathrm{O}_{2}: 2.2 \mathrm{vpm}$, humidity: $2 \mathrm{vpm}$ ) atmosphere at $1200{ }^{\circ} \mathrm{C}$ for 2 hours. $\mathrm{Mg}$ powders were evaporated during sintering and $\mathrm{Mg}$ vapor also aided $\mathrm{Ar}$ gas to create protective atmosphere in the furnace against oxidation. The heating rate of the furnace was kept constant at $10{ }^{\circ} \mathrm{C} / \mathrm{min}$ to prevent collapse of compacts during melting and evaporation of $\mathrm{Mg}$ powders.

Mechanical behavior of processed porous Ti-6Al-4V alloys was characterized by monotonic compression tests, which were carried out according to ISO 13314:2011 standard at a crosshead speed of $0.1 \mathrm{~mm} / \mathrm{min}$ with $100 \mathrm{kN}$ capacity screw driven electromechanical testing machine (Instron 5582, Instron Co. LTD., Norwood, USA) at room temperature. Strain measurements were conducted with an advanced non-contact video extensometer (Instron 2663-821, Instron Co. LTD., Norwood, USA). Three specimens were tested for each condition. Young's modulus of each tested Ti-6Al-4V foam was measured from the slope of the linear portion of stress-strain diagram while yield stress was determined by $0.2 \%$-offset method. Maximum strength of the S-DP foam was determined as the onset of densification, rapid increase in the stress-strain curve, while it was the maximum stress value attained for S-CIP and NS-CIP foams. 


\section{RESULTS AND DISCUSSION}

\section{Porous Ti-6Al-4V alloys produced from spherical powder}

SEM analyses have revealed that produced foams were composed of two different pore structures, namely macropores and micropores (Figure 3). Macropores, which were intentionally created by the evaporation of magnesium, have homogenous distribution, spherical geometry and interconnections to other pores (Figure $3 \mathrm{a}, \mathrm{b}$ ). On the other hand, irregular shaped micropores were formed due to insufficient sintering of Ti-6Al-4V powders (Figure 3c, d).

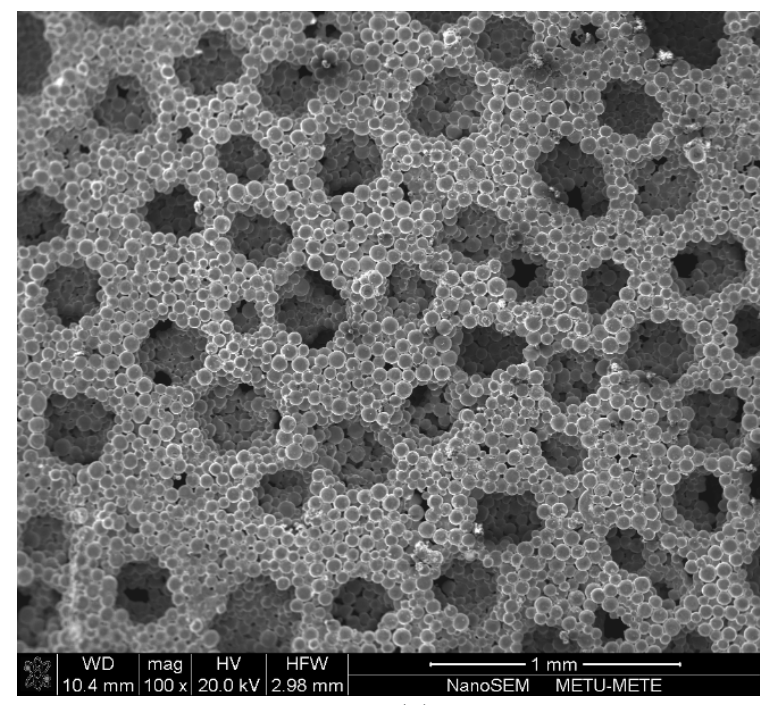

(a)

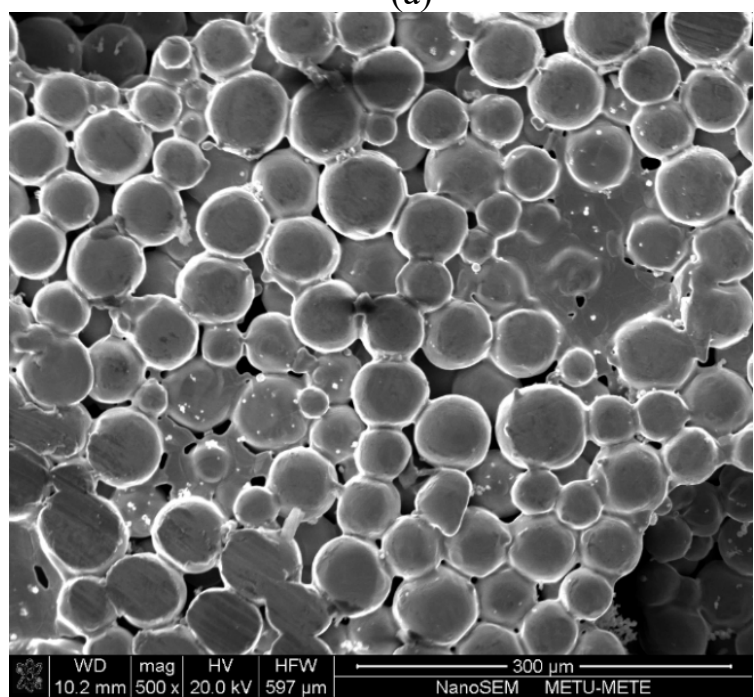

(c)

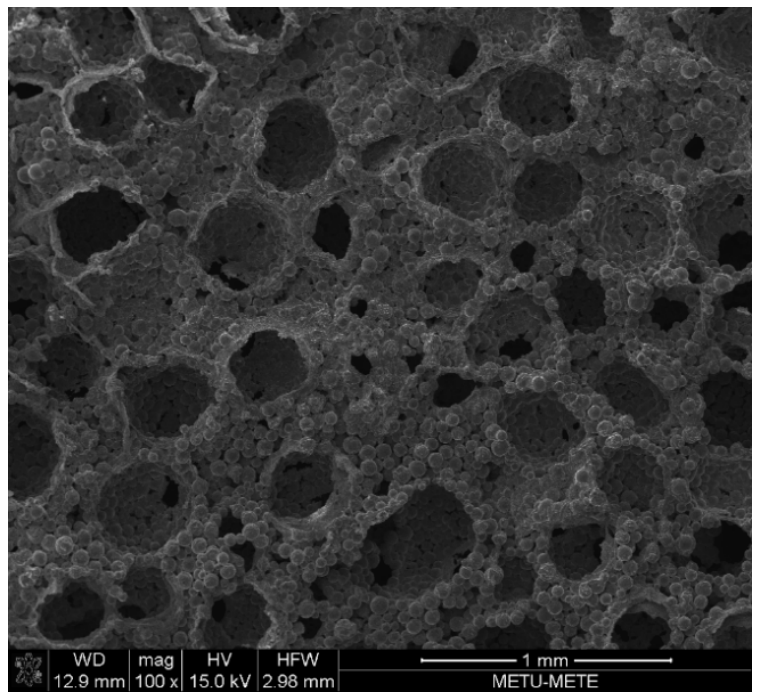

(b)

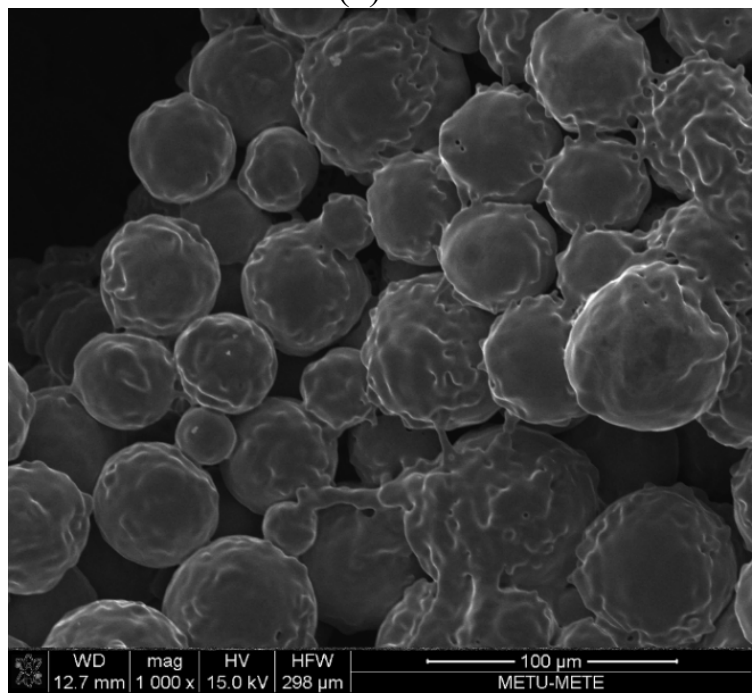

(d)

Figure 3. SEM micrographs: macropore distribution of (a) S-DP and (b) S-CIP foams, micropores at the sintering necks of (c) S-DP and (d) S-CIP foams

All of the produced Ti-6Al-4V foams have interconnected, spherical macropores with relatively homogeneous distribution independent from the compaction technique. However, the extent of sintering and accordingly the amount of microporosity was observed to be highly dependent on the compaction conditions. From the comparison of Figure $3 \mathrm{c}$ and Figure $3 \mathrm{~d}$, it can be observed that the compaction of the powders was not enough and accordingly sintering was insufficient when CIP 
technique was used. On the other hand, it is obvious that S-DP foams have also considerable amount of microporosity on the sintering necks.

The difference in the compaction ratio of the S-DP and S-CIP foams was attributed to the lower compaction pressure applied by CIP. As it was obvious from both PSD measurements and SEM micrographs, spherical Ti-6Al-4V powder has a very narrow size range. When the spherical shape of the powders was combined with the narrow size range, the compaction became difficult. The applied load with hydraulic press was $500 \mathrm{MPa}$ in die-compaction while it was $300 \mathrm{MPa}$ in CIP, giving rise to the difference in compaction behavior. Accordingly, it was found that $300 \mathrm{MPa}$ is not sufficient to compact the spherical Ti-6Al-4V powders even the distribution of load was homogeneous.

The difference in compaction amount has significantly affected the results of monotonic compression tests (Figure 4). Both yield and ultimate tensile strength of S-CIP foam was observed to be lower than that of S-DP foam. The powders that have loosely sintered could not sustain the applied load and premature collapse has occurred in S-CIP foam. It was observed that the mechanical response of S-DP and S-CIP foams was similar to each other, the only difference being the densification stage. Both of the foams were initially elastically deformed upto yield point and deformation proceeded by wavy plateau region immediately after yielding. However, the increase in the stress due to densification of S-DP foam was not observed for S-CIP foam since the struts were too weak to sustain the load even after collapse of S-CIP foam. A comparable case of insufficient sintering is observed in the research of Kalantari et al., where sintering temperature was $900{ }^{\circ} \mathrm{C}$. The foams produced by Kalantari et al. exhibited a yield strength of $90 \mathrm{MPa}$, which is similar to S-CIP foams; however, they suffered from strength drop that resulted in lower energy absorbing capacity than that of S-CIP foams [31].

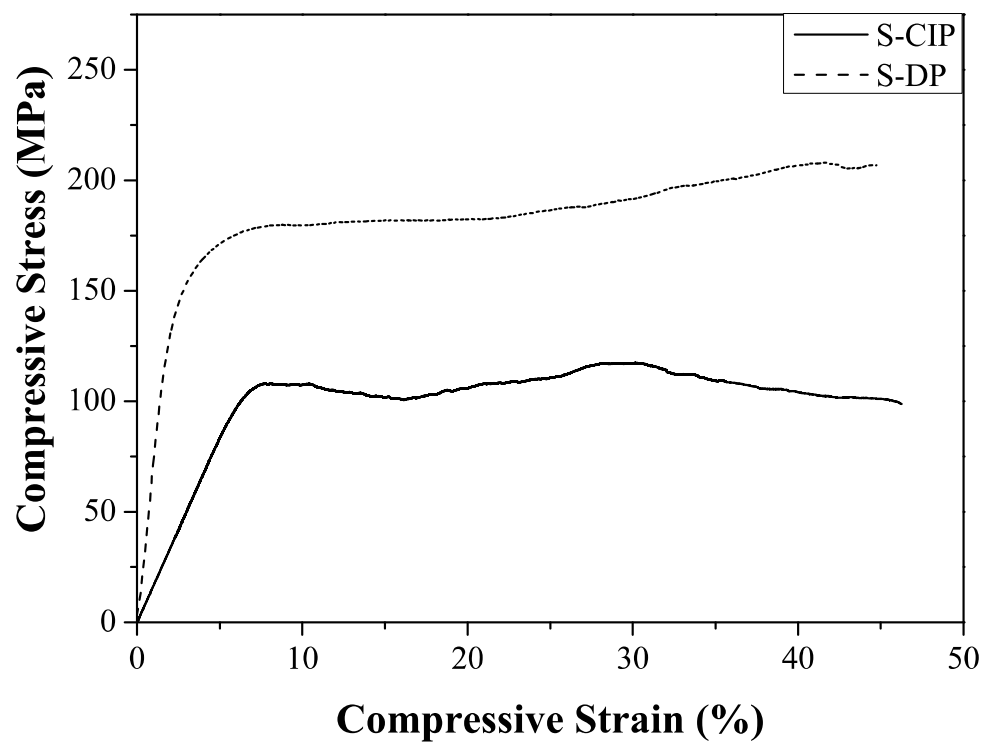

Figure 4. Monotonic compression behavior of S-DP and S-CIP foams

Porous Ti-6Al-4V alloys produced from nonspherical powder

NS-CIP foams were produced to decrease the microporosity content since the origin of microporosity was the insufficient compaction of powders due to their spherical shape. The reason of employing CIP instead of die pressing as the compaction technique was the fact that intricate shapes can be manufactured by CIP technique.

SEM micrographs indicated that the interconnected spherical macropores are also present in NS-CIP foam (Figure 5a). However, the microporosity content was significantly reduced as given in Figure 5b. 
Ti-6Al-4V powders have interlocked each other due to their irregular shape resulting in better sintering.

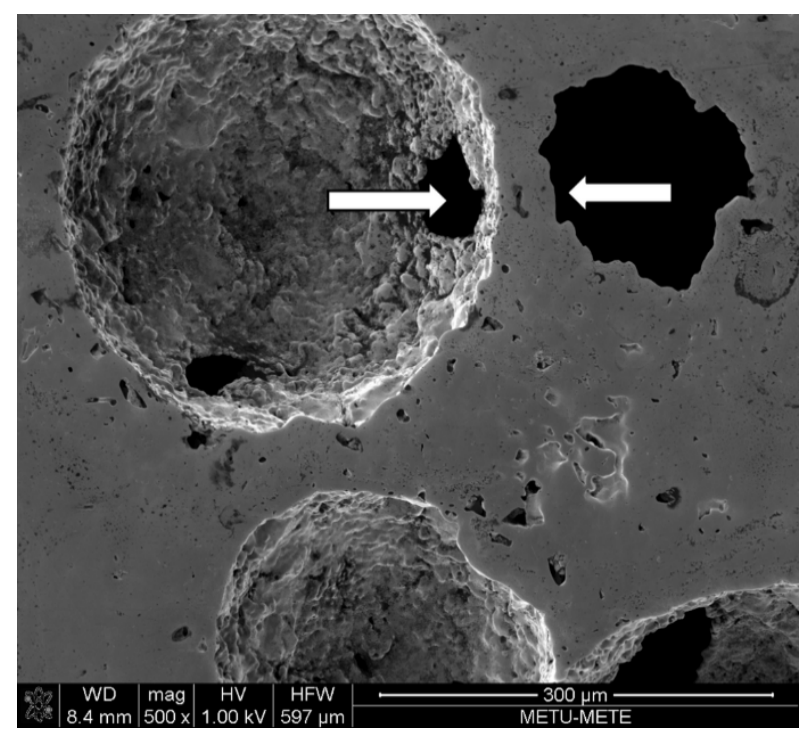

(a)

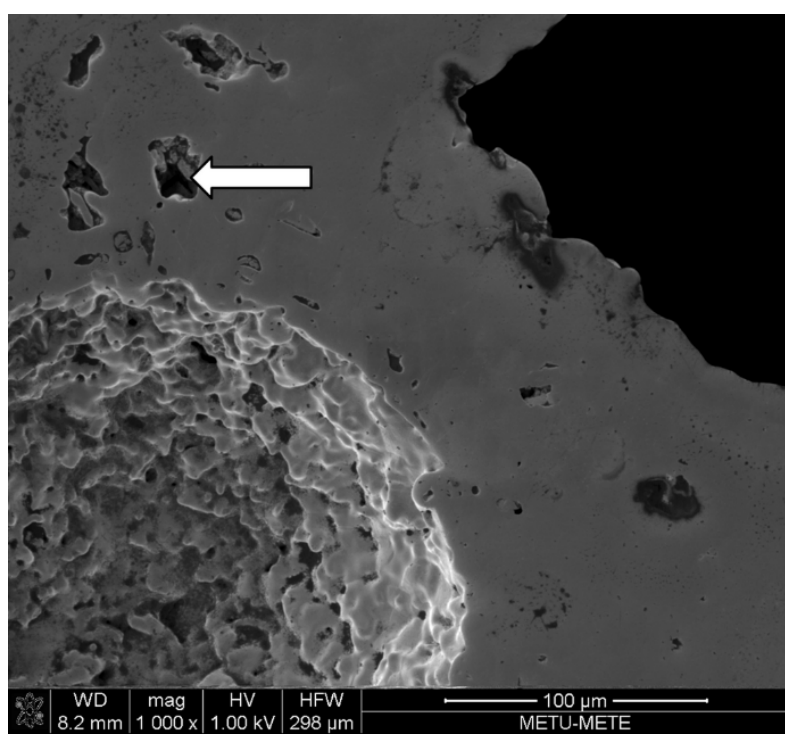

(b)

Figure 5. (a) Interconnection spherical macropores (interconnection is indicated by white arrows) and (b) microporosity (indicated by white arrow)

The better sintering conditions achieved by using nonspherical powder resulted in an increase in both yield and ultimate strength values as given in Table 1. However, it was observed that the energy storage capacity of S-DP foam was still higher than that of NS-CIP foam.

Table 1. Mechanical properties of the produced Ti-6Al-4V foams where $\sigma_{\mathrm{y}}$ is the yield strength, $\sigma_{\max }$ is maximum compressive strength, $\mathrm{E}$ is Young's modulus.

\begin{tabular}{|c|c|c|c|}
\hline & S-DP & S-CIP & NS-CIP \\
\hline$\sigma_{\mathrm{y}}(\mathrm{MPa})$ & 125 & 92 & 172 \\
\hline$\sigma_{\max }(\mathrm{MPa})$ & 185 & 117 & 210 \\
\hline $\mathrm{E}(\mathrm{GPa})$ & 7.99 & 1.66 & 5.30 \\
\hline
\end{tabular}

NS-CIP foam has also displayed a different compression behavior with respect to both S-CIP and SDP foams (Figure 6). The latter two foams displayed a wavy plateau region after yield strength due to a decrease in porosity content after collapse of the strut groups, which leads to transient strengthening. However, NS-CIP foams have a steeper decreasing trend after ultimate strength has achieved. The difference was believed to be due to the higher strength of individual struts that prevents regional collapse of strut groups, which was the origin of transient strengthening in S-DP and S-CIP foams [25]. Bhattarai et al. produced similar Ti-6Al-4V foams from non-spherical powders and coarser space holder particles via hydraulic pressing. The yield strength of the foams is similar with that of NS-CIP foam. In addition, both type of foams show a sudden and high drop in their stress carrying capacity just after yielding. This can be caused by local failure of the struts such that non-spherical powders were mechanically engaged during compaction. After the stress drop Bhattarai et al.'s foams exhibit a pseudodensification stage, whereas NS-CIP did not showed that behavior, which might be caused by insufficient compaction [32].

The results obtained from NS-CIP foam were promising since it has observed that better strength can be achieved even with lower compaction pressures applied by CIP. Furthermore, complex shaped 
foams, which were determined according to the requirements of application, can be produced by CIP and increasing CIP pressure can enhance mechanical properties.

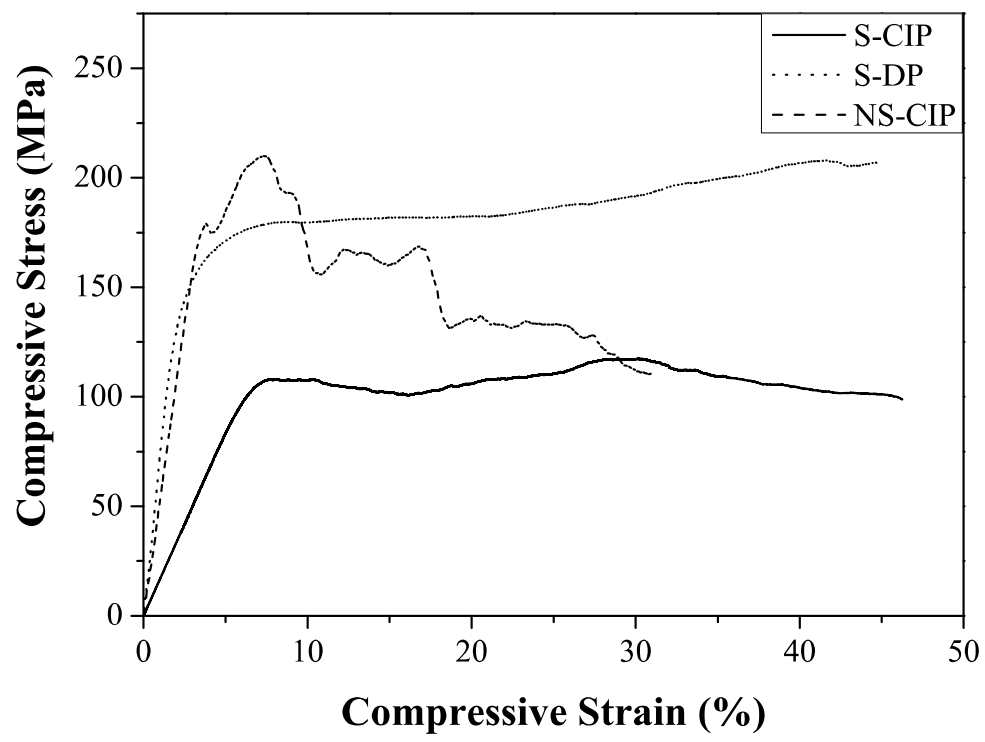

Figure 6. The monotonic compression behavior of S-DP, S-CIP and NS-CIP foams

\section{CONCLUSIONS}

Both spherical and nonspherical Ti-6Al-4V powders, which were mixed with $60 \mathrm{vol} \% \mathrm{Mg}$ powder, were sintered at $1200^{\circ} \mathrm{C}$ for 2 hours. Two different compaction techniques were employed for spherical powders, namely CIP and DP. It was observed that $300 \mathrm{MPa}$ pressure was not enough for compaction of spherical powders with CIP. On the contrary, the same pressure resulted in the lowest microporosity when the nonspherical Ti-6Al-4V powder was used since irregularly shaped powders interlocked each other. The change in microporosity has affected the mechanical properties leading to better yield and ultimate strength. However, the energy storage capacity of S-DP foam was still higher than NS-CIP foam. It was concluded that CIP can be a better alternative to DP when nonspherical powder was used; similar pressure was applied; and intricate shape of product is required.

\section{REFERENCES}

[1] Hartman AD, Gerdemann SJ, Hansen JS. Producing lower-cost titanium for automotive applications J. Min. Metals Mater. Soc., 50:16-19, 1998.

[2] Boyer RR. An overview on the use of titanium in the aerospace industry Mater. Sci. Eng. A, 213:103-114, 1996.

3] Geetha M, Singh AK, Asokamani R, Gogia AK Ti based biomaterials, the ultimate choice for orthopaedic implants - A review Prog. Mater. Sci., 54:397-425, 2009.

[4] Rack HJ, Qazi JI. Titanium alloys for biomedical applications Mater. Sci. Eng. C, 26:1269-1277, 2006.

[5] Niinomi M. Mechanical properties of biomedical titanium alloys Mater. Sci. Eng. A, 243:231-236, 1998. 
[6] Spoerke ED, Murray NG, Li H, Brinson LC, Dunand DC, Stupp SI. A bioactive titanium foam scaffold for bone repair Acta Biomater. 1:523-33, 2005.

[7] Heinl P, Müller L, Körner C, Singer RF, Müller FA. Cellular Ti-6Al-4V structures with interconnected macro porosity for bone implants fabricated by selective electron beam melting Acta Biomater., 4:1536-44, 2008.

[8] Navarro M, Michiardi A, Castaño O, Planell JA. Biomaterials in orthopaedics J. R. Soc. Interface, 5:1137-58, 2008.

[9] Jacobs JJ, Sumner DR, Galante JO. Mechanisms of bone loss associated with total hip replacement Orthop. Clin. North Am., 24:583-90, 1993.

[10] Karachalios T, Tsatsaronis C, Efraimis G, Papadelis P, Lyritis G, Diakoumopoulos G. The longterm clinical relevance of calcar atrophy caused by stress shielding in total hip arthroplasty $\mathrm{J}$. Arthroplasty, 19:469-475, 2004.

[11] Arpak B, Araz K, Nakaş İ, Bor Ş, Nergiz İ. The mechanical characterization and in vivo evaluation of porous tini as graft material Funct. Mater. Lett., 05:1250023, 2012.

[12] Willie BM, Yang X, Kelly NH, Merkow J, Gagne S, Ware R, Wright TM, Bostrom MP. Osseointegration into a novel titanium foam implant in the distal femur of a rabbit J. Biomed. Mater. Res. B. Appl. Biomater., 92:479-488, 2010.

[13] Kienapfel H, Sprey C, Wilke A, Griss P. Implant fixation by bone ingrowth J. Arthroplasty, 14:355-368, 1999.

[14] Banhart J. Manufacture, characterisation and application of cellular metals and metal foams Prog. Mater. Sci., 46:559-632, 2001.

[15] Clemow AJ, Weinstein AM, Klawitter JJ, Koeneman J, Anderson J. Interface mechanics of porous titanium implants J. Biomed. Mater. Res., 15:73-82, 1981.

[16] Esen Z, Bor Ş. Processing of titanium foams using magnesium spacer particles. Scr. Mater., 56:341-344, 2007.

[17] Nilles JL, Lapitsky M. Biomechanical investigations of bone-porous carbon and porous metal interfaces J. Biomed. Mater. Res., 7:63-84, 1973.

[18] Sypeck DJ, Parrish PA, Wadley HNG. Novel Hollow Powder Porous Structures MRS Proc., 521:205, 2011.

[19] Murray N, Dunand DC. Microstructure evolution during solid-state foaming of titanium Compos. Sci. Technol., 63:2311-2316, 2003.

[20] Li JP, Li SH, Van Blitterswijk CA, Groot de KA. Novel porous Ti6Al4V: characterization and cell attachment J. Biomed. Mater. Res. A, 73:223-33, 2005.

[21] Murr LE, Gaytan SM, Medina F, Martinez E, Martinez JL, Hernandez DH, Machado BI, Ramirez DA, Wicker RB. Characterization of Ti-6Al-4V open cellular foams fabricated by additive manufacturing using electron beam melting Mater. Sci. Eng. A 527:1861-1868, 2010. 
Aşık et al. / Anadolu Univ. J. of Sci. and Technology A-Appl. Sci. and Eng. 18 (1) - 2017

[22] Heinl P, Rottmair A, Körner C, Singer RF. Cellular Titanium by Selective Electron Beam Melting Adv. Eng. Mater., 9:360-364, 2007.

[23] Balla VK, Bose S, Bandyopadhyay A. Understanding compressive deformation in porous titanium Philos. Mag., 90:3081-3094, 2010.

[24] Nakaş Gİ, Dericioğlu AF, Bor Ş. Monotonic and cyclic compressive behavior of superelastic TiNi foams processed by sintering using magnesium space holder technique Mater. Sci. Eng. A, 582:140-146, 2013.

[25] Bansiddhi A, Dunand DC. Shape-memory NiTi foams produced by replication of $\mathrm{NaCl}$ spaceholders Acta Biomater., 4:1996-2007, 2008.

[26] Bram M, Stiller C, Buchkremer HP, Stöver D, Baur H. High-Porosity Titanium, Stainless Steel, and Superalloy Parts Adv. Eng. Mater., 2:196-199, 2000.

[27] Mansourighasri A, Muhamad N, Sulong AB. Processing titanium foams using tapioca starch as a space holder J. Mater. Process. Technol., 212:83-89, 2012.

28] Gu YW, Yong MS, Tay BY, Lim CS. Synthesis and bioactivity of porous Ti alloy prepared by foaming with $\mathrm{TiH}_{2}$ Mater. Sci. Eng. C, 29:1515-1520, 2009.

[29] Chino Y, Dunand DC. Directionally freeze-cast titanium foam with aligned, elongated pores Acta Mater., 56:105-113, 2008.

[30] Esen Z, Bor Ş. Characterization of Ti-6Al-4V alloy foams synthesized by space holder technique Mater. Sci. Eng. A, 528:3200-3209, 2011.

[31] Kalantari SM, Arabi H, Mirdamadi S, Mirsalehi SA. Biocompatibility and compressive properties of Ti-6Al-4V scaffolds having Mg element. J Mech Behav Biomed Mater 48, 183-191,2015

[32] Bhattarai SR, Khalil KA-R, Dewidar M, Hwang PH, Yi HK, Kim HY. Novel production method and in-vitro cell compatibility of porous Ti-6Al-4V alloy disk for hard tissue engineering. J. Biomed. Mater. Res., 86A: 289-299, 2008. 